\title{
Telling Them Like It Is: The Role of Economic and Environmental Factors in Single Mothers' Discussions with Their Children ${ }^{1}$
}

\author{
Vonnie C. McLoyd ${ }^{2}$ \\ University of Michigan \\ Leon Wilson \\ Wayne State University
}

Uses interview data from a sample of 155 single mothers of at least one child between the ages of 10 and 17 to assess the impact of financial strain and welfare status (Aid to Families with Dependent Children) on three areas of maternal functioning: (a) belief in the appropriateness of telling children about family problems, (b) disclosure of financial matters and personal worries to children, and (c) curbing of children's material consumption and social experiences as a strategy to ease financial strain. Also examined whether other environmental conditions (i.e., negative life events, social support), demographic factors, and mothers' mental health account for significant variation in these three outcomes once financial strain and welfare status are taken into account. Financial strain, but not welfare status, was a significant predictor of all three dependent variables. Age of child, number of children in the household who

\footnotetext{
${ }^{1}$ This research was supported in part by a Faculty Scholar Award in Child Mental Health from the William T. Grant Foundation and a postdoctoral fellowship from the Rockefeller Foundation, both awarded to the first author. During the collection and analyses of data, the second author was supported by a Rodney-Dubois-Mandela postdoctoral fellowship from the Center for Afro-American and African Studies at the University of Michigan and a faculty research award from the College of Labor, Urban and Metropolitan Affairs at Wayne State University. We thank the families who participated in the study and the staffs of the Michigan Department of Social Services and the Ypsilanti, Michigan, public schools for their cooperation. We also acknowledge with gratitude the assistance of Liese Hull, Eve Trager, Reshall James, Lauren Lewis, Shannon Nelson, Valerie Day, Patty Rich, Jean Wend, Wendy DuBoe, Natasha Lifton, and Robert Allen in data collection and coding.

${ }^{2}$ All correspondence should be sent to Vonnie C. McLoyd, Center for Human Growth and Development, 300 N. Ingalls, University of Michigan, Ann Arbor, Michigan 48109.
} 
were older than the target child, and maternal belief predicted mothers' reported tendency to discuss financial matters and personal problems with the target child. These factors, however, were unrelated to mothers' tendency to curb children's consumption and social/recreational experiences.

The number of families headed by women with children under 18 doubled between 1970 and 1980 and continues to rise (Smith, 1986). Absence of a husband in the household can have numerous consequences for the single mother including diminished economic well-being (approximately $50 \%$ of female-headed families are poor and dependent on public welfare), lack of regular companionate interaction with an adult, and lack of an adult partner to share parenting and household management responsibilities (Fox \& Inazu, 1982; Garfinkel \& McLanahan, 1986). These consequences, in turn, can influence parenting and parent-child relations. For example, Weiss (1979) found that following divorce, mothers required their children to do more household tasks, encouraged or permitted them to play a more active role in household management and family decision making, and shared more information with them about the family's financial difficulties and the mother's personal problems. These parenting behaviors apparently were intended to ease role strain and compensate for the economic and social deficits deriving from the husband's absence. Recent empirical studies comparing the behavior of adolescents in female-headed versus twoparent households corroborate some of Weiss's observations and document the interdependence of marital and parental role systems (Dornbusch et al., 1985; Fox \& Inazu, 1982).

The present study moves beyond this comparative framework and identifies factors that account for variation among single mothers in three areas of maternal functioning: (a) child-rearing belief (i.e., the appropriateness of telling children about family problems even if such action is expected to cause emotional distress in the child), (b) disclosure of financial matters and personal worries to children, and (c) curbing of children's material consumption and social experiences as a strategy to ease financial strain (i.e., cutbacks). Each of these dependent variables is seen as reflecting or pertinent to maternal protectiveness, and ultimately, the maturity expectations mothers hold for their children. Of primary interest is whether diminished psychological and social well-being among single mothers predict increased maturity expectations of children once economic well-being is taken into account. Indicators of psychological and social well-being used in this study are depressive symptomatology, emotional and informational support, and the occurrence of negative life events. Also assessed in the present study is the relation between maternal belief and behavior and the 
extent to which maternal belief accounts for the relation between psychological and social well-being and maternal behavior.

It is important to identify the sources of individual differences in the areas of maternal functioning examined in the present study, in part, because of the latter's potential to influence children's psychological functioning. Tentative evidence exists linking high exposure to single mothers' lamentations about personal and financial problems to increased psychological distress in children (McLoyd \& Wilson, 1990; Weiss, 1979). In the same vein, the risk of depression and emotional difficulties following parental loss (through death or divorce) during childhood has been found to be greater among individuals who as children felt burdened by the surviving or custodial parent's need for emotional support and overall demands, and were pressured by the surviving or custodial parent to take on the role of the parent who was lost (Breier et al., 1988). Specification of the factors that govern parents' tendency to limit children's material consumption (e.g., purchase of clothes) and social experiences is of interest partly because such constraints can lead to loss in children's social status among peers and, in turn, contribute to feelings of social rejection, unhappiness, and social sensitivity (Elder, 1974).

\section{ECONOMIC STRESS, MATERNAL BELIEF, AND MATERNAL BEHAVIOR}

Virtually nothing is known of the antecedents of parents' beliefs about the appropriateness of informing children about family problems. However, prior research on parents's socialization goals and attitudes bears on this issue and, in particular, provides a solid basis for prediction about the relation between economic stress and this particular domain of parental belief. It is well documented that working-class parents and lower class parents, compared to middle-class parents, put less emphasis on happiness in the child as a child-rearing goal (Duvall, 1946; Kohn, 1959; Lurie, 1974). In keeping with this finding, working-class and lower class parents are thought to be less imbued than middle-class parents with the notions that childhood should be a time of boundless happiness and carefree existence and that parental responsibility includes the self-conscious provision of "happiness" to the child (Seabrook, 1982). These differences might be due to the fact that lower status parents have fewer material resources, larger families, and more mental health problems than higher status parents. Consequently, they are in a less advantageous position than higher status parents to afford the luxury of happiness as a high-priority child-rearing goal and child-rearing practices that further this goal (L. W. Hoffman, 1984; 
McLoyd, 1990). If economic strain reduces the saliency of happiness as a child-rearing goal and discourages the sentimentalization of childhood, it is also likely to minimize the perceived value of quarantining children from the responsibilities and problems of "real" (i.e., adult) life that might kindle unhappiness and psychological distress in the child. Following this line of reasoning, we expected that greater economic stress would predict an increased tendency by mothers to endorse the idea of disclosing to children potentially upsetting information about family problems.

In contrast to our lack of knowledge about the relation between economic well-being and parents' belief about information sharing, much is known about how economic stress influences parental behavior and the experience of childhood. Ethnographic and empirical research suggests that poverty prevents parents from offering their children the level of psychological and even physical protection and comfort typically extended by middle-class parents. Poverty encourages parents to structure more mature relationships with their children marked by openness and honesty, to demand emotional precocity that often exceeds their children's chronological years, and to increase the level of certain kinds of instrumental competence expected of their children (Coles, 1964; Ladner, 1972). For example, lowerclass and working-class children, compared to middle-class children, have been found to perform more tasks essential to the day-to-day functioning of their households, although this finding has not been consistently replicated (Goodnow, 1988; Newson \& Newson, 1976; Zill \& Peterson, 1982). That poor children themselves perceive these greater maturity expectations is perhaps best captured in Claude Brown's (1965) autobiographical novel about growing up in poverty. Reno, a friend of Claude's, gives the following characterization of childhood in Harlem:

\footnotetext{
Man, ... they ain't got no kids in Harlem. I ain't never seen any. I've seen some real small people actin' like kids. They were too small to be grown, and they might've looked like kids, but they don't have any kids in Harlem, because nobody had time for a childhood ... Do you ever remember bein' a kid? Not me ... kids are happy, kids laugh, kids are secure. They ain't scared-a nothin' . . I I ain't never been a kid, man. I don't ever remember bein' happy and not scared. I don't know what happened ... but I think I missed out on that childhood thing, because I don't ever recall bein' a kid. (p. 295)
}

These considerations led us to expect that mothers experiencing more economic stress would be less psychological protective of their children and, in particular, would (a) discuss financial matters and personal worries with their children more frequently, and (b) more readily curb their children's material consumption and social experiences for the purpose of easing economic strain. 


\section{THE RELATION OF PSYCHOLOGICAL AND SOCIAL WELL-BEING TO MATERNAL BELIEF AND BEHAVIOR}

Perhaps the more important contribution of the present study is its examination of whether maternal mental health, negative life events, and emotional and informational support account for significant variation in maternal belief and behavior once economic stress is taken into account. We know of no studies that directly examine these relations. In most investigations of the relation of parental behavior to psychological and environmental factors, the underlying construct at issue is parental nurturance rather than protectiveness per se. Furthermore, most of these studies focus on mothers of infants and young children (see McLoyd, 1990, for a review of these studies), whereas our sample comprised mothers of adolescents or children at the threshold of adolescence. Nonetheless, these studies and the conceptual frameworks that guide them provide a sound basis for hypotheses in the present study because, although conceptually distinct, nurturance and protectiveness are likely to be fostered by similar psychological states and environmental conditions.

Poor mental health among mothers is a strong correlate of reduced responsiveness to children's dependency needs and increased punitiveness toward children (Conger, McCarty, Yang, Lahey, \& Kropp, 1984; Downey \& Coyne, 1990; Longfellow, Zelkowitz, \& Saunders, 1982; McLoyd, 1990). Evidence also exists that mothers experiencing more psychological distress demand more extensive involvement in household maintenance from their children and place greater responsibility on them (Longfellow et al., 1982). These studies constituted the basis for our expectation that less positive maternal mental health, because it heightens mothers' level of self-involvement, would predict stronger endorsement of the idea of discussing family problems with children, an increased tendency to discuss financial matters and personal problems with the child, and an increased tendency to curb children's material consumption and social experiences.

Negative life events were expected to be similarly related to the dependent variables. Research indicates that mothers who have experienced more negative life events report more psychological distress and behave in a more contentious and less nurturant and responsive manner toward their children (Belle, 1984; G. Brown, Bhrolchain, \& Harris, 1975; Gersten, Langner, Eisenberg, \& Simcha-Fagan, 1977; Makosky, 1982). Negative life events deplete emotional reserves and, hence, may lessen the mother's capacity to keep her worries private (at least in terms of the child) or her willingness to buffer the child from material and social deprivation. Therefore, we hypothesized that negative life events would be positively related 
to discussions, cutbacks, and endorsement of the idea of discussing family problems with children.

The relation of emotional and informational support to mothers' belief and behavior is also examined in the present study. Investigations of mothers of infants and young children report that those receiving higher levels of emotional support are more nurturant toward their children and less likely to nag, scold, ridicule, or threaten them (Weinraub \& Wolf, 1983). Emotional support appears to have a salutary effect on parenting behavior by making mothers feel less isolated, less overwhelmed by their parenting situation, more gratified by the maternal role, and more satisfied with their offspring (Crnic \& Greenberg, 1987; Zur-Szpiro \& Longfellow, 1982). In addition, it can foster a sense of efficacy and confidence in one's ability to deal with problems and promote a redefinition of problems so that they are less threatening (Sandler, Miller, Short, \& Wolchik, 1989). These psychological benefits may increase mothers' ability or willingness to shelter children from problems and privations within the means available to them. For example, receipt of high levels of emotional support might motivate a mother to prioritize family cutbacks, such that those having a direct effect on the child (e.g., reducing expenditures for the child's clothing and educational activities) are introduced only after cutbacks affecting the mother (e.g., reducing expenditures for the mother's clothing and recreational activities) have been made and found to be insufficient to reduce the family's economic strain. Hence, we predicted that emotional support would lessen mothers' tendency to discuss financial matters and personal problems, weaken their endorsement of such behavior, and decrease their tendency to ease financial strain at the expense of children's material consumption and social experiences.

Few data exist about the relation between parental behavior and informational support. In one of the few studies of this issue, Cotterell (1986) found that maternal warmth, mother-child play, maternal cognitive stimulation, and frustration tolerance were positively associated with informational support (defined in this study as useful advice about managing one's home and children). The present study examines a more general type of informational support, defined here as help in defining, understanding, and coping with problematic events that arise during the course of daily living (Cohen \& Wills, 1985). Informational support was expected to parallel emotional support in its influence on maternal belief and behavior.

In recent years, researchers have devoted much effort to documenting and clarifying the relation between parents' ideas and behavior in various domains (Goodnow, 1984). Maternal belief was expected to be a strong predictor of self-reported behavior in the present study, although it cannot be determined whether ideas actually instigate or justify actions. In addition 
to testing the relation between belief and behavior, we sought to determine if maternal belief accounted for the relation between maternal behavior and well being.

\section{CHILD CHARACTERISTICS AND MATERNAL BEHAVIOR}

The present study examines the child's age and sex and the number of siblings in the household who were older than the target child as predictors of maternal behavior. Research indicates that parents of chronically ill children disclose less information about the diagnoses and treatment implications of the illness to preadolescent children than adolescent children because they believe that the former are less able to both process the information accurately and regulate emotional arousal in stressful situations (Chesler, Paris, \& Barbarin, 1986; Claflin \& Barbarin, 1991). In line with this finding, we hypothesized that mothers' sensitivity to developmental differences in children's emotional maturity and ability to handle distressing information would lead them to disclose their worries and financial concerns and curb material consumption and social activities less frequently if the child is younger rather than older. The presence in the household of older siblings of the children was expected to decrease the frequency with which mothers disclosed worries and financial concerns with the target child and curbed the latter's material consumption and social activities because older siblings represent more mature interlocutors and typically assume a more active role in the resolution of family problems (Elder, 1974). No predictions were made about the relation between maternal behavior and sex of the target child.

\section{METHOD}

\section{Recruitment Procedures and Study Participants}

Although the present study is limited to data from mothers, it is based on a larger study that called for interviewing both the mother and one of her children ranging in age between 10 and 17 years (target child). Recruitment procedures targeted female-headed families that were experiencing varying levels of economic difficulty and lived in two small, adjoining cities located in southeastern Michigan (one a predominantly middle-class college town with a population of approximately 110,000 , the other a predominantly working-class town with a population of about 25,000 ). The county in which these cities are located consistently has the lowest unem- 
ployment rate (4-6\%) in the state of Michigan. Participation was limited to single mothers (separated, divorced, never married) and children living in the same household.

Participants were recruited through two sources, the local office of the Michigan Department of Social Services and a local middle school and senior high school. Mothers were sent a letter that (a) described the goals of the study and the interview procedure, (b) assured confidentiality of data, and (c) indicated that each mother-child dyad would receive $\$ 20$ as compensation. Accompanying the letter was a one-page screening questionnaire requesting contact information and information about the mother's marital status, household composition, and work status. The letter requested that mothers interested in participating in the study complete the questionnaire and return it to the investigator in a self-addressed, stamped envelope enclosed with the letter.

The Michigan Department of Social Services was prohibited from releasing to researchers the names and addresses of welfare recipients. However, it agreed, first, to randomly select 500 women who lived in the local area and met the study's inclusionary criteria and, second, to send the recruiting and screening materials to these individuals through its office. To discourage suspicion that the study was being conducted by or for the Michigan Department of Social Services or that the latter would have access to confidential information provided by the respondent, all materials bore our university research office as the return address. These procedures also guaranteed that our research staff would learn a woman's identity only if she returned the questionnaire or if the postal service returned the correspondence to our research office because of an inadequate address. Five hundred sets of the screening/recruitment materials were prepared by the research staff; each set was enclosed in an envelope and delivered to personnel in the Department of Social Services who, in turn, affixed address labels on the envelopes and mailed them to the 500 selected mothers.

A total of 58 letters were returned undelivered because the address was incorrect or the mother had moved and left no forwarding address. One hundred fifty-three mothers completed and returned the questionnaire (35\% of 442). Limited personnel assistance at the Michigan Department of Social Services made it impossible to send reminders to mothers who did not return the questionnaire. Of the 153 mothers who returned the questionnaire, 35 were excluded from the study because they did not meet the study's inclusionary criteria. Research assistants made attempts to contact each of the remaining 118 mothers either by telephone or in person (if the potential participant did not have a telephone or the telephone was not in service) to schedule a time for an interview. Completed interviews were obtained from 83 of these mothers. It proved impossible to complete 
interviews with the remaining 35 for a variety of reasons (e.g., being unable to establish contact with the mother to schedule an interview, change in the mother's or child's decision to participate in the study).

Participants were also recruited through a local middle school and high school that enrolled children from primarily working-class backgrounds. A total of 207 children from four classrooms representing each grade level (6th-9th) were identified on the basis of school records as living in female-headed households. The mothers of these children were sent the recruitment letter and screening questionnaire described above; $117(57 \%)$ ) returned the screening questionnaire and indicated their and their child's willingness to participate in the study: 26 of these mothers indicated that they were married, so they were excluded from the study. Completed interviews were obtained from 72 of the remaining 91 mothers.

The total sample, then, comprised 155 single mothers who ranged in age from 25 to 58 years $(M=35)$. Table I summarizes selected demographic characteristics of the sample of mothers and target children.

\section{Measures}

A $1 \frac{1}{2}$ - to 2 -hour structured interview was conducted with each mother in her home or another location chosen by the mother (approximately $10 \%$ of the interviews were conducted in locations other than respondents' homes). The interview consisted of questions developed expressly for the research project and several existing, widely used scales which, in some cases, were adapted for use in the present investigation. Questions about maternal behavior (i.e., disclosure and cutbacks) explicitly asked the mother about her behavior toward the target child. The interviewers were female graduate and undergraduate students, all of whom were either African American or Anglo American. We were unable to systematically match race of interviewer and race of respondent.

\section{Criterion Variables}

(a) To assess belief about the appropriateness of discussing family problems with children, each mother was asked to indicate on a 4-point scale her level of agreement with the following statement: "Parents should tell their children about the difficult problems that affect the family even if this information causes the child to worry" $(1=$ strongly disagree, $4=$ strongly agree). (b) Disclosure of financial matters and mothers' personal worries was assessed with two items $(r=.54)$. Each mother indicated on a 5-point scale how often she talked with the target child about her personal 
Table I. Demographic Characteristics of Sample

\begin{tabular}{|c|c|c|}
\hline Characteristic & $N$ & $\%$ \\
\hline \multicolumn{3}{|l|}{ Marital status ${ }^{a}$} \\
\hline Separated or divorced & 94 & 61 \\
\hline Never married & 57 & 37 \\
\hline Widowed & 4 & 3 \\
\hline \multicolumn{3}{|l|}{ Ethnic classification } \\
\hline African American & 85 & 55 \\
\hline Anglo American & 62 & 40 \\
\hline Asian American & 6 & 4 \\
\hline Hispanic American & 2 & 1 \\
\hline \multicolumn{3}{|l|}{ Age of mother ( $M=35$ years) } \\
\hline $25-30$ & 20 & 13 \\
\hline 30.1-35 & 58 & 37 \\
\hline $35.1-40$ & 41 & 26 \\
\hline $40.1-45$ & 22 & 14 \\
\hline Over 45 & 11 & 7 \\
\hline Missing data & 3 & 2 \\
\hline \multicolumn{3}{|l|}{ Welfare status } \\
\hline \multicolumn{2}{|c|}{ Receiving Aid to Families with } & \\
\hline income $=\$ 6,482 /$ year $)$ & 95 & 61 \\
\hline \multicolumn{3}{|c|}{ Not receiving Aid to Families with } \\
\hline income $=\$ 16,354 /$ year) & 60 & 39 \\
\hline \multicolumn{3}{|c|}{ Age of target child ( $M=13.9$ years) } \\
\hline 12 or less & 23 & 15 \\
\hline $12.1-13$ & 27 & 17 \\
\hline $13.1-14$ & 30 & 19 \\
\hline $14.1-15$ & 29 & 19 \\
\hline $15.1-16$ & 25 & 16 \\
\hline 16.1-17 & 21 & 14 \\
\hline \multicolumn{3}{|l|}{ Gender of target child } \\
\hline Female & 85 & 55 \\
\hline Male & 70 & 45 \\
\hline
\end{tabular}

$\overline{a^{a}}$ Thirteen women were living with a partner, but were included in the sample because these living arrangements were of an occasional nature or of recent origin.

worries and, second, about the family's financial situation $(1=$ never, $5=$ very often). (c) Our measure of cutbacks in the child's material consumption and social/recreational experiences was an 8-item scale in which the mother indicated how often in the past 3 months $(1=$ never, $5=$ very often) she attempted to reduce family expenses by intervening in the target child's behavior (e.g., told the child to cut down on the amount of food he or she eats at home, to lower the heat, to use home electrical appliances less often) and refusing to grant the child's wishes (e.g., refused to buy the child an article of clothing or some other item the child wanted, told the 
child that he or she cannot go to or participate in some social or recreational event or invite friends to have dinner or a snack at his/her home).

\section{Predictor Variables}

Two aspects of mothers' mental health were examined, namely, depression and anxiety/somatization. Depression was measured with the Center for Epidemiological Studies Depression Scale (CES-D) which consists of 20 items representing the major components of the depressive syndrome: depressed mood, feelings of guilt and worthlessness, helplessness, and changes in eating and sleeping patterns. Each respondent indicated on a 4-point scale how frequently she experienced these symptoms during the past week ( $1=$ rarely or none of the time, $4=$ most or all of the time). Anxiety/somatization was assessed with the anxiety and somatization scales of the Hopkins Symptom Checklist (Derogatis, Lipman, Rickels, Uhlenhuth, \& Covi, 1974). The mother indicated on a 5-point scale how often she had each of 21 problems and complaints (e.g., headaches, nervousness, mind going blank) during the past 30 days $(1=$ not at all, $5=$ a great deal). Because scores on the two measures were highly correlated, the scales were combined to constitute a single indicator of the mother's mental health $(\alpha=.73)$. Both the CES-D and the Hopkins symptom Checklist have very high internal consistency and adequate test-retest reliability and discriminant validity across a wide variety of demographic characteristics including age, race (African American and Anglo American), and educational level (Derogatis et al., 1974; Radloff, 1977).

Two indicators of economic well-being were used. The first, $A F D C$ status, reflected whether or not the family was receiving public welfare assistance in the form of Aid to Families with Dependent Children. The second reflected financial strain, or the perception of being unable to make ends meet, and was based on the mother's response to three close-ended questions: "How difficult is it for you to meet the monthly payments on your family's bills?" ( $1=$ not difficult at all, $5=$ extremely difficult or impossible), "In general, how do your family finances usually work out at the end of the month? Do you find that you usually end up with some money left over, just enough to make ends meet, or not enough money to make ends meet?" $(1=$ some money left over, $3=$ not enough money to make ends meet), and "In the past three months, how often have you decided not to buy something you had been planning to purchase for yourself or for your children?" $(1=$ not at all, $5=$ a great deal $)(\alpha=.66)$. Higher scores indicate greater financial strain. 
Items from Barrera, Sandler, and Ramsay's (1981) Inventory of Socially Supportive Behaviors (ISSB) were used to assess the frequency with which the mother was the recipient of supportive actions. Emotional support, based on the mother's response to 10 items, reflected the extent to which the mother was the recipient of actions that communicated that she is loved and held in high esteem (e.g., "let you know that you did something well," "expressed interest and concern in your well being," "comforted you by showing physical affection") $(\alpha=.91)$. Three items assessed receipt of informational support, defined as help in defining, understanding, and coping with problematic events ("told you what he or she did in a situation that was similar to yours," "gave you some information to help you understand a situation that you were in," "helped you understand why you didn't do something well") $(\alpha=.75)$. For each item, mothers rated the frequency with which the described behavior occurred during the preceding month using a 5 -point scale $(1=$ never, $5=$ very often). No information was gathered about the identity of the individual who engaged in each supportive act. Although the ISSB contained other subscales, the two used in our analyses had the highest level of internal consistency. Barrera et al. generated items for the ISSB partly on the basis of interviews with single, low-income mothers about the types of helping behaviors they had received in response to important problems they had experienced. The scale has been shown to have adequate test-retest reliability, internal consistency, and discriminant validity in samples of college students (Barrera et al., 1981).

Information about the occurrence of negative life events experienced by the mother, the target child, and other family and household members within the past 12 months was gathered in a 53-item inventory (yes/no format) administered to the mother. This inventory, consisting of events deemed negative or undesirable, was adapted from Garmezy, Masten, and Tellegen's (1985) Life Events Questionnaire for adolescents and their parents, Coddington's (1972) Stressful Life Events Inventory for Children, and Makosky's (1982) Life Events Scale for low-income women. The inventory is a broad-based indicator of the level of adaptation demands placed on the mother, as it includes events that she experienced directly, as well as events experienced by immediate family and/or household members (e.g., physical assault of one of her children, loss of employment by a household member) that probably required adaptation or adjustment of varying degrees by the mother.

Information about the mother's age and race, the child's age and sex, and the composition of the household was gathered in the interview with the mother. 


\section{RESULTS}

The means and standard deviations for the variables used in the analyses are presented in Table II. Table III reports the intercorrelations among the criterion and predictor variables. In general, the correlations among predictor variables pose no serious problems for the analyses undertaken. We were concerned about the consequences of the high correlation (.71) between emotional and informational support for the multivariate analyses. Accordingly we examined the variance inflation factor for all the models that included these two predictors. Examination of this diagnostic did not reveal any serious multicollinearity problems.

We present three multivariate models. First, we assessed the relation of several factors to mothers' belief, specifically, their level of endorsement of the idea of discussing family problems with children. These factors, along with other explanatory variables (age and sex of child, and number of older siblings), were then examined as predictors of two maternal behaviors directed specifically towards the target child: (a) discussion of financial matters and the mother's personal worries and (b) cutting back on the child's material consumption and social/recreational experiences to ease financial strain. Finally, we examined the relation of these predictors to (a) and (b) when maternal belief about sharing problems with children is taken into account.

Consistent with the intent of the study, incremental regression models were used to examine the independent effects of different sets of predictors. Mothers in the sample differed in terms of age and ethnicity, characteristics that have often been linked to parenting behavior (Conger, McCarty, Yang,

Table II. Means and Standard Deviations for Criterion and Predictor Variables

\begin{tabular}{lcc}
\hline \multicolumn{1}{c}{ Predictor } & $M$ & $S D$ \\
\hline $\begin{array}{l}\text { Maternal belief } \\
\text { Disclosure of financial and }\end{array}$ & 2.77 & 0.91 \\
$\quad$ personal matters & 3.26 & 1.02 \\
Cutbacks in child's & & \\
$\quad$ consumption & 1.86 & 0.67 \\
Financial strain & 2.37 & 0.92 \\
Mother's mental health & 1.60 & 0.37 \\
Negative life events & 6.32 & 4.33 \\
Emotional support & 3.26 & 0.87 \\
Informational support & 2.40 & 1.02 \\
Age of child & 13.94 & 1.85 \\
No. of older siblings in & & 1.24 \\
\hline household & 2.45 & \\
\hline
\end{tabular}




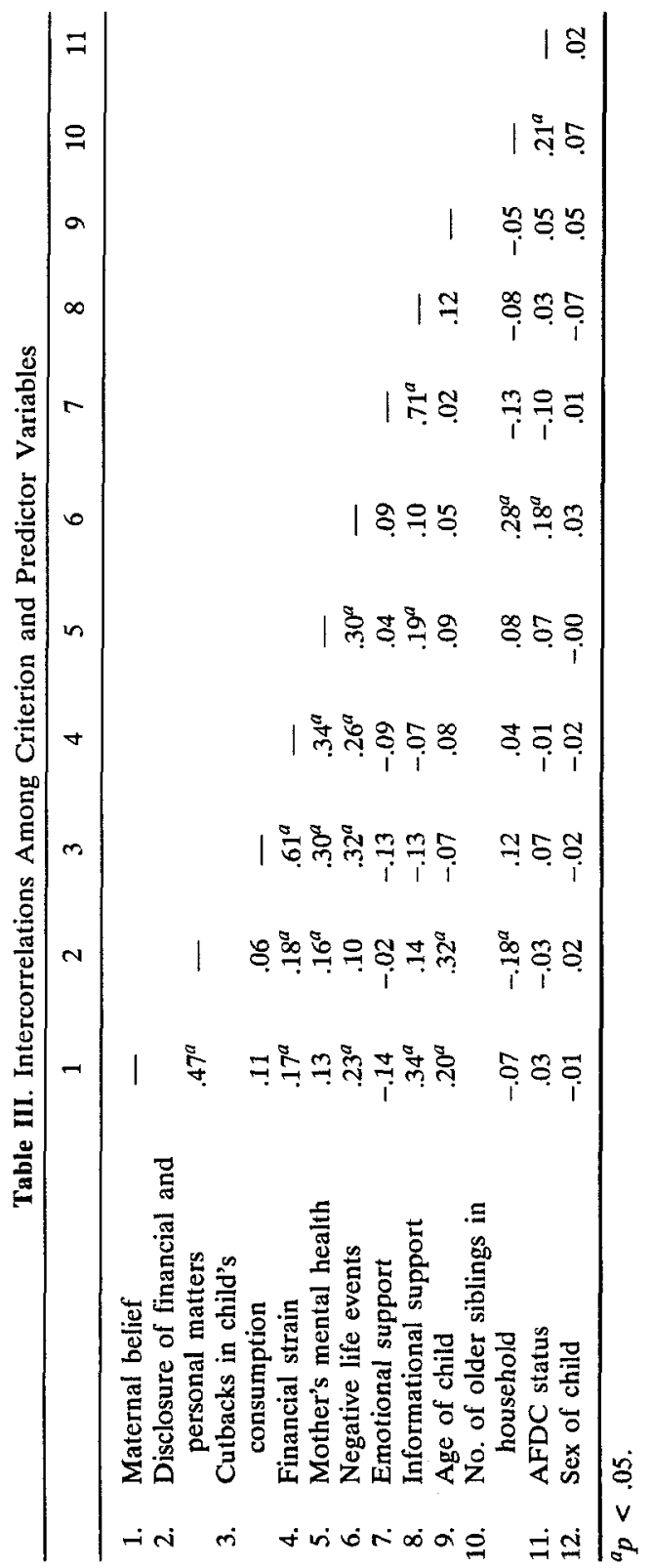


Lahey, \& Burgess, 1984; McLoyd, 1990; Stevens \& Duffield, 1986). Hence, although we made no predictions about the relationship of ethnicity and age of mothers to the dependent variables, our preliminary analyses included these two variables as predictors. The results indicated that neither of these variables was significantly related to the three dependent variables. Therefore, ethnicity and age of mothers, and interaction variables are not included in the models reported below. Also, for each of the models, we tested for interaction effects among various predictor variables and found no significant relationships.

\section{Belief in Sharing Family Problems with Children}

In all of the regression analyses, variables at each step are entered as a block. Table IV presents the standardized coefficients for the predictors of mothers' belief in sharing family problems with children. For this analysis, we use a two-step procedure. The first step assesses the influence of the two indicators of economic well-being. As Table IV indicates, our hypothesis that economic hardship would predict stronger belief in sharing family problems with children was only partially supported. Financial strain, but not AFDC status, is significantly and positively related to mothers' belief in sharing family problems with children. Together, these variables account for a mere $2 \%$ (adjusted) of the variation in the dependent variable.

In Step 2 of the analysis, we entered the additional variables and examined the increase in variance explained once financial strain and welfare status are controlled. The results indicate that an additional 15\% (adjusted) of the variance is explained in mothers' belief in sharing family problems

Table IV. Standardized Regression Coefficients for the Predictors of Maternal Belief

\begin{tabular}{|c|c|c|c|c|}
\hline \multirow[b]{2}{*}{ Predictors } & \multicolumn{2}{|c|}{$\begin{array}{c}\text { Step 1 } \\
\left(R^{2} \text { adj. }=.02\right)\end{array}$} & \multicolumn{2}{|c|}{$\begin{array}{c}\text { Step } 2 \\
\left(R^{2} \text { adj. }=.17\right)\end{array}$} \\
\hline & $\beta$ & Error & $\beta$ & Error \\
\hline Financial strain & $.17^{b}$ & .08 & $.16^{b}$ & .08 \\
\hline AFDC (dummy) ${ }^{a}$ & -.03 & .08 & -.03 & .08 \\
\hline Mother's mental health & - & - & -.07 & .08 \\
\hline Negative life events & - & - & $.18^{b}$ & .08 \\
\hline Emotional support & - & - & $-.23^{c}$ & .11 \\
\hline Informational support & - & - & $.51^{d}$ & .11 \\
\hline
\end{tabular}

\footnotetext{
${ }^{a}$ AFDC Recipients Coded 1.

${ }^{b} p<.05$.

$c_{p}<.02$.

$d_{p}<.001$.
} 
with children. The $F$ test for the increment in variance explained is very significant $(F=4.75, p<.001)$. Most of the increase in variation is due to the effect of informational support, which accounts for about $12 \%$ of the additional variance. Contrary to our prediction, however, the direction of the effect of this variable is positive. Mothers who received more informational support believed more strongly that family problems should be discussed with children. In contrast, and consistent with our expectation, emotional support is significantly and negatively related to mothers' belief. Also in line with our prediction, mothers who reported higher incidence of negative life events had significantly stronger beliefs in sharing problems with their children than mothers who reported fewer negative life circumstances. Mental health is unrelated to maternal belief.

\section{Discussion of Financial Matters and Personal Worries}

Table $\mathrm{V}$ presents the results of our analysis of the predictors of maternal discussions in three steps. Similar to the analyses above, the first step examines the impact of the two indicators of economic well-being. As with maternal belief, financial strain, but not AFDC status, predicted a greater tendency by mothers to talk with the target child about her worries

Table V. Standardized Regression Coefficients for the Predictors of Disclosure of Financial and Personal Matters

\begin{tabular}{|c|c|c|c|c|c|c|}
\hline \multirow[b]{2}{*}{ Predictors } & \multicolumn{2}{|c|}{$\begin{array}{c}\text { Step } 1 \\
\left(R^{2} \text { adj. }=.02\right)\end{array}$} & \multicolumn{2}{|c|}{$\begin{array}{c}\text { Step } 2 \\
\left(R^{2} \text { adj. }=.15\right)\end{array}$} & \multicolumn{2}{|c|}{$\begin{array}{c}\text { Step } 3 \\
\left(R^{2} \text { adj. }=.27\right)\end{array}$} \\
\hline & $\beta$ & Error & $\beta$ & Error & $\beta$ & Error \\
\hline Financial strain & $.18^{c}$ & .08 & .13 & .08 & .07 & .08 \\
\hline AFDC (dummy) ${ }^{a}$ & .03 & .08 & .05 & .08 & .04 & .07 \\
\hline Mother's mental health & - & - & -.05 & .08 & .08 & .08 \\
\hline Negative life events & 一 & - & .01 & .08 & .02 & .08 \\
\hline Emotional support & - & 一 & $-.23^{c}$ & .11 & -.14 & .10 \\
\hline Informational support & - & 一 & $.25^{c}$ & .11 & .06 & .11 \\
\hline Age of child & - & - & $.26^{e}$ & .08 & $.21^{d}$ & .07 \\
\hline Sex of child (dummy) ${ }^{b}$ & - & - & .04 & .08 & .03 & .07 \\
\hline \multicolumn{7}{|l|}{ No. of older siblings } \\
\hline in household & - & - & $-.20^{c}$ & .07 & $-.16^{c}$ & .07 \\
\hline Belief & - & - & - & - & $.38^{e}$ & .08 \\
\hline
\end{tabular}

${ }^{a}$ AFDC Recipients Coded 1.

${ }^{b}$ Girls Coded 1.

$c_{p}<.05$.

$d_{p}<.02$.

$e_{p}<.001$. 
and financial concerns. The variance explained by these two indicators of economic well-being is only $2 \%$ (adjusted). At Step 2 of the analyses, the additional variables increment the model significantly $(F=4.12, p<.001)$ by $13 \%$ (adjusted).

The introduction of the additional variables at Step 2 reduced the effect of financial strain to nonsignificance $(p<.08)$. Higher levels of emotional support, but lower levels of informational support, predicted a decreased tendency by mothers to discuss money matters and personal worries. In line with our expectation, the younger the target child, and the more older siblings living in the household, the less likely mothers were to discuss finances and personal problems with the target child. Sex of child is unrelated to frequency of discussion; in addition, tests of interaction effects revealed that neither the child's sex nor age modified the relations between other predictor and criterion variables. Contrary to our hypotheses, poor mental health and negative life events are unrelated to the frequency of discussions of financial matters and personal worries.

In the final step of the analyses, we added mothers' belief about sharing problems into the model. The results indicate that an additional $12 \%$ (adjusted) of the variance is explained $(F=3.80, p<.001)$. While the effects of the age of the target child and the number of older siblings in the household remained fairly constant, the effects of the social support variables are reduced to nonsignificance. We found no significant interaction effects between mothers' belief and the two social support variables and, therefore, conclude that once mothers' beliefs are taken into account, the effects of emotional and informational support are no longer significant.

In summary, then, our final model indicates that maternal conviction about the propriety of discussing personal and financial matters with their children is the strongest predictor of reported maternal practice. The age of the child in question and the number of older siblings in the household with the target child also influence mothers' tendency to disclose personal and financial concerns.

\section{Cutbacks in Child's Material Consumption and Social/Recreational Experiences}

As can be seen in Table VI, financial strain, but not AFDC status, predicted more frequent cutbacks in children's material consumption and social/recreational experiences. Financial strain is a particularly strong predictor $(\beta=.61)$. At Step 1, the indicators of economic well-being accounted for $40 \%$ (adjusted) of the variation in the dependent variable. The addi- 
Table VI. Standardized Regression Coefficients for the Predictors of Cutbacks in Child's Material Consumption and Social/Recreation Experiences

\begin{tabular}{|c|c|c|c|c|c|c|}
\hline \multirow[b]{2}{*}{ Predictors } & \multicolumn{2}{|c|}{$\begin{array}{c}\text { Step } 1 \\
\left(R^{2} \text { adj. }=.40\right)\end{array}$} & \multicolumn{2}{|c|}{$\begin{array}{c}\text { Step } 2 \\
\left(R^{2} \text { adj. }=.40\right)\end{array}$} & \multicolumn{2}{|c|}{$\begin{array}{c}\text { Step } 3 \\
\left(R^{2} \text { adj. }=.40\right)\end{array}$} \\
\hline & $\beta$ & Error & $\beta$ & Error & $\beta$ & Error \\
\hline Financial strain & $.61^{e}$ & .06 & $.54^{e}$ & .07 & $.53^{e}$ & .07 \\
\hline AFDC (dummy) ${ }^{a}$ & -.08 & .06 & -.04 & .07 & .05 & .07 \\
\hline Mother's mental health & - & - & .09 & .07 & .10 & .07 \\
\hline Negative life events & - & - & $.15^{c}$ & .07 & $.15^{c}$ & .07 \\
\hline Emotional support & - & - & -.03 & .09 & -.02 & .09 \\
\hline Informational support & - & - & -.09 & .09 & -.11 & .10 \\
\hline Age of child & - & - & -.11 & .06 & -.12 & .06 \\
\hline Sex of child (Dummy) ${ }^{b}$ & - & - & -.02 & .06 & -.02 & .06 \\
\hline No. of older siblings & & & & & & \\
\hline in household & - & - & .02 & .07 & .03 & .07 \\
\hline Belief & - & 一 & - & - & .03 & .07 \\
\hline
\end{tabular}

${ }^{a}$ AFDC Recipients Coded 1.

${ }^{b}$ Girls Coded 1.

${ }^{c} p<.05$.

${ }_{p}<.02$.

$e_{p}<.001$.

tional variables entered at Step 2 did not significantly increment the amount of variance explained.

However, consistent with our prediction, negative life events predicted greater cutbacks in children's consumption and experiences, but none of the other variables entered at Step 2 were significantly related to the dependent variable. Maternal belief, entered at Step 3, had practically no effect on the model. The adjusted percentage of variance explained is similar at both steps and the coefficient for maternal belief is nonsignificant. Financial strain remained a strong predictor with the introduction of the additional variables at Step 2 and Step 3. In regard to mothers' tendency to check their children's material consumption and social/recreational experiences, then, mothers seem to react mainly on the basis of their perceived economic condition and, to some extent, in relation to the occurrence of negative life events.

\section{DISCUSSION}

In his call for a cultural-ecological approach to the study of parenting and development, Ogbu (1981) argued that an adequate study of child rearing in a given population must probe into individuals' conscious models of 
how children should be raised and the antecedents of their models. The present study of single mothers represents a modest step in this direction by, first, identifying environmental factors that predict single mothers' belief about the appropriateness of holding potentially distress-inducing discussions with their children about family problems and, second, assessing the link between maternal belief and reported behavior. In general, the picture that emerges is that, as predicted, mothers who were facing particularly hard times as indicated by greater financial strain, more negative life events, and receipt of lower levels of emotional support are more likely to endorse the practice of telling children about family problems. In short, the value for disclosing information about family problems increased with an increase in the presence of environmental stressors, a finding consistent with Ladner's (1972) observations. Furthermore, the present findings indicate that maternal belief may mediate the impact of emotional and informational support on maternal behavior.

The links between environmental conditions and belief documented in the present study may be partly mediated by mothers' perceptions of the harshness of threat posed by their environment. Central themes that emerged from the comments of mother who strongly endorsed this practice were that individuals and society are often indifferent, if not hostile to one's well-being (As one mother said, "Children have to learn that it's a cruel world.") and that the development of essential instrumental competencies and psychological attributes is impeded if children are pampered and spared exposure to the family's problems. Discussion of family problems was seen by some of these mothers as a natural, well-suited context for teaching children skills and coping strategies needed to take care of themselves as adults in high-risk environments. From their perspective, achieving this socialization goal outweighed the potential cost to the child of emotional distress or unhappiness resulting from disclosures. In short, we believe that these mothers' endorsement of disclosure and discussion of family problems as a proper way to raise children was partly based on their notions of the characteristics their children need to succeed. These notions, in turn, seemed linked to their experiences in and perceptions of their environment (Ogbu, 1981).

While strong endorsement of the practice seemed rooted in its perceived positive instrumental function, strong disapproval appeared to center around its potential to undermine the child's emotional health. Several mothers expressed the belief that children's psychological functioning is best served if they are protected from, rather than exposed to, potential stressors. As one mother put it, "Children shouldn't be in stressful situations ... it causes a lot of problems." Our findings suggest that mothers are more likely to take this stance if they (and their families) experience 
less financial strain and fewer negative life events, and receive higher levels of emotional support. These circumstances may lessen the perceived perniciousness of the environment and consequently diminish the value of discussion of family problems as a way of "toughening" children. We know that neighborhood conditions such as the availability of social and parenting support are related both to parenting behavior and to parents' evaluation of their neighborhoods as a place to live and raise their children (Garbarino \& Sherman, 1980). What is now needed is research that specifies how various characteristics of neighborhoods and other extrafamilial contexts influence parents' constructions of childhood, ideas about proper parenting, and theories of success, and how these factors influence parental behavior. Priority also should be given to determining whether or not these relations are cultural/race-specific.

The belief and reported behaviors of mothers in the present study were related to certain predictor variables in similar and meaningful ways. Higher levels of emotional support and less financial strain predicted decreased discussion of financial matters and personal problems as well as a less favorable view of discussing family problems with children. Although emotional support appeared to buffer children from mother's discussions of problems, it had no effect on the degree to which mothers required their children to make social and material sacrifices to cope with economic strain; neither did mothers' mental health, the age or sex of the child, or the number of older siblings in the household. This aspect of maternal behavior was governed primarily by the perceived level of economic strain experienced by the family, being largely impervious to the social and psychological variables examined in the present study.

Although sex of child neither predicted maternal behavior nor modified relations among variables examined in the present study, this and related issues should be revisited in future studies employing more extensive measures of information disclosure. Evidence from a number of studies suggests that parents are more psychologically protective of their daughters than their sons, raising the possibility that parents modify both the frequency and quality of their disclosures of emotionally distressing information in response to the child's gender. For example, investigations of children's response to divorce indicate that parents fight less and their fights are shorter in duration in the presence of girls than boys. They also provide more emotional support to girls than boys (Hetherington, StanleyHagan, \& Anderson, 1989). Concern about girls' capacity for emotional regulation in the face of stressful situations may lead single mothers to discuss certain problems less readily with daughters than sons, or to attenuate the level of emotional distress communicated in discussions with daughters. Alternatively, girls' heightened tendency (compared to boys') to 
share in the emotions of others (e.g., to feel distressed when others are distressed) (M. L. Hoffman, 1977) may encourage single mothers to disclose personal worries and emotional distress to daughters more frequently than to sons, to emphasize instrumental coping strategies less frequently in discussions with daughters than sons, and to show a preference for daughters over sons as confidants. Research on these interesting questions may provide insight into the origins of gender differences in coping behavior.

In the present study, single mothers reported discussing personal worries and financial matters less frequently with younger children than older children. This finding is consistent with evidence that age of child partly governs the amount of information parents disclose to chronically ill children about the illness (Chesler et al., 1986; Claflin \& Barbarin, 1991). Future research is needed to determine if the frequency, quality, and psychological effects of problem-focused discussions about a range of family problems vary as a function of the child's developmental level.

The relation of informational support to mothers' belief and practice was contrary to prediction and worked in a direction opposite to emotional support. Informational support predicted greater, rather than lesser, endorsement of the idea of discussing family problems, and increased, rather than decreased, maternal discussion of money and personal problems. This pattern of finding probably reflects a conceptual problem with the measure of informational support. This measure was based on items from the ISSB, an instrument explicitly intended to assess support received in the recent past. As others have noted, however, this instrument confounds the need for and use of support with the availability of support. Consequently, it may to some degree reflect psychological distress, which leads to increased use of support (Cohen \& Wills, 1985). This conceptual ambiguity may explain why informational support was positively related to the criterion variables of the present study and why other investigators have found social support as measured by the ISSB to be positively associated with symptomatology and life events measures (Barrera, 1981; Cohen \& Hoberman, 1983). In the present study, the three-item measure of informational support assessed the frequency with which a mother received information about what another person did in a situation similar to the one confronting the mother, or information that helped her understand either a situation she was in or why she did something poorly. Unlike the items used in the present study to measure receipt of emotional support, these items make reference not only to a specific situation but also to a situation that is problematic, negative, and potentially stressful. It is likely then that receipt of these acts of informational support was precipitated to a large extent by the situation, the psychological distress it caused, and the resulting tendency 
of individuals to seek out support. Seen in this light, it is not surprising that high levels of informational support predicted greater endorsement of the idea of discussing family problems, and increased discussion by mothers of money and personal problems.

Welfare status consistently failed to account for significant variation in the dependent variables, perhaps because the nonpoverty status women, while not receiving public welfare assistance, were not sufficiently and comfortably above the poverty line to meaningfully distinguish their economic well-being from women on AFDC. In contrast, financial strain, or the perception of being unable to make ends meet, was a significant predictor of maternal belief and denial, and a marginally significant predictor of maternal discussion of finances. A number of researchers have investigated the effects of financial strain on psychological and family functioning, using indicators very similar to our measure (Elder, Conger, \& Foster, 1989; Kelley, Sheldon, \& Fox, 1985; Kessler, Turner, \& House, 1988; Lempers, Clark-Lempers, \& Simons, 1989). These studies are congruent with the present findings in demonstrating that financial strain has greater explanatory power in analyses of psychological and family functioning than static categories such as unemployment, job loss, or income loss.

The presence of an older sibling has been found to lessen the effects of undesirable events and circumstances on the socioemotional functioning of poor African American and Chicano children (Sandler, 1980). Although the mechanisms by which older siblings buffer stress are not well understood, serving as a confidant might be one way by which this occurs (Belle \& Longfellow, 1983). Belle and Longfellow found that siblings were more often chosen as confidants by older children than younger children and in households with more older children and fewer younger children. Reducing younger siblings' exposure to stressors, such as mothers' complaints about personal and financial problems, may be another way by which older siblings foster psychological well-being in younger siblings (McLoyd \& Wilson, 1990; Weiss, 1979). In the present study, a greater number of older siblings was associated with a decreased tendency by the mother to talk with the target child about personal worries and financial concerns. This finding may indicate that the availability of older children to listen to the mother's concerns reduces the likelihood that younger children will be the target of these maternal expressions which, in turn, may enhance their psychological well-being. Documenting these hypothesized linkages requires looking at the female-headed family as a system. Increasingly, researchers have focused on how mother-child interaction influences sibling relationships (Bryant, 1989; Watson-Gegeo \& Gegeo, 1989), but very little research has been done to document how the mother's interaction with one child influ- 
ences her interaction with that child's sibling(s). This is an intriguing issue that merits investigation in both two-parent and female-headed families.

Although the present study yields interesting and meaningful findings, it is limited in four ways. First, the low response rate of the targeted sample may have introduced a number of self-selection biases that constrain the generalizability of the findings. Second, the study relied exclusively on selfreport data. The degree to which these data correspond to mothers' actual behavior is unknown. A third limitation is its lack of detail concerning maternal belief and disclosure about different kinds of family problems. Whether single mothers look favorably or unfavorably on discussing family problems with their children, and whether they engage the child in discussion about these problems, may be influenced by the extent, sensitivity, and controllability of the problem. Future research employing more extensive measures of maternal belief and disclosure may uncover relations undetected in the present study. Finally, the study does not assess the nature and affective quality of mothers' disclosures and discussions of financial matters and personal problems. These communications are likely to reflect considerable variation in quality, ranging from ones marked by complaints, lamentations, and emotionality (i.e., venting one's frustration) to ones that focus on strategies the family will use to actively cope with the problem in question. Similarly, the tone of discussions about family problems can be primarily hopeful or despairing. Research is needed to determine how different environmental factors such as those examined in the present study influence the quality of single mothers' problem-related disclosures and discussions and how these factors relate to children's psychological well-being. Certain affective patterns of maternal behavior may foster psychological resiliency in economically disadvantaged children, whereas others may contribute to feelings of powerlessness, pessimism, depression, and the use of palliative forms of coping that seek only to dull the reality of problems and stressors.

\section{REFERENCES}

Barrera, M. (1981). Social support in the adjustment of pregnant adolescents: Assessment issues. In B. H. Gottlieb (Ed.), Social networks and social support (pp. 69-96). Beverly Hills: Sage.

Barrera, M., Sandler, I., \& Ramsay, T. (1981). Preliminary development of a scale of social support: Studies on college students. American Journal of Community Psychology, 9, 435447.

Belle, D. (1984). Inequality and mental health: Low income and minority women. In L. Walker (Ed.), Women and mental health policy (pp. 135-150). Beverly Hills: Sage. 
Belle, D., \& Longfellow, C. (1983, August). Turning to others: Children's use of confidants. Paper presented at the annual meeting of the American Psychological Association, Toronto, Canada.

Breier, A., Kelsoe, J., Kirwin, P., Beller, S., Wolkowitz, O., \& Pickar, D. (1988). Early parental loss and development of adult psychopathology. Archives of General Psychiatry, 45, 987993.

Brown, C. (1965). Manchild in the promised land. New York: New American Library.

Brown, G., Bhrolchain, M., \& Harris, T. (1975). Social class and psychiatric disturbance among women in an urban population. Sociology, 9, 225-254.

Bryant, B. (1989). The child's perspective of sibling caretaking and its relevance to understanding social-emotional functioning and development. In P. Zukow (Ed.), Sibling interaction across cultures: Theoretical and methodological issues (pp. 143-164). New York: Springer-Verlag.

Chesler, M., Paris, J., \& Barbarin, O. (1986). Telling the child with cancer: Parental choices to share information with ill children. Journal of Pediatric Psychology, 11, 497-516.

Claflin, C., \& Barbarin, O. (1991). Does "telling" less protect more? Relationships among age, information disclosure, and what children with cancer see and feel. Journal of Pediatric Psychology, 16, 169-191.

Coddington, R. D. (1972). The significance of life events as etiological factors in the diseases of children, II: A study of a normal population. Journal of Psychosomatic Research, 16, 205-213.

Cohen, S., \& Hoberman, H. (1983). Positive events and social supports as buffers of life change stress. Joumal of Applied Social Psychology, 13, 99-125.

Cohen, S., \& Wills, T. (1985). Stress, social support, and the buffering hypothesis. Psychological Bulletin, 98, 310-357.

Coles, M. (1964). Children of crisis. New York: Little Brown.

Conger, R., McCarty, J., Yang, R., Lahey, B., \& Burgess, R. (1984). Mother's age as a predictor of observed maternal behavior in three independent samples of families. Journal of Marriage and the Family, 46, 411-424.

Conger, R., McCarty, J., Yang, R., Lahey, B., \& Kropp, J. (1984). Perception of child, childrearing values, and emotional distress as mediating links between environmental stressors and observed maternal behavior. Child Development, 55, 2234-2247.

Cotterell, J. L. (1986). Work and community influences on the quality of child rearing. Child Development, 57, 362-374.

Crnic, K., \& Greenberg, M. (1987). Maternal stress, social support, and coping: Influences on early mother-child relationship. In C. Boukydis (Ed.), Research on support for parents and infants in the postnatal period (pp. 25-40). Norwood, NJ: Ablex.

Derogatis, L., Lipman, R., Rickels, K., Uhlenhuth, E., \& Covi, L (1974). The Hopkins Symptom Checklist (HSCL). In P. Pichot (Ed.), Psychological measurements in psychopharmacology (Vol. 7, pp. 79-110). Paris: Karger.

Dornbusch, S., Calsmith, J., Bushwall, S., Ritter, P., Leiderman, H., Hastorf, A., \& Gross, R. (1985). Single parents, extended households, and the control of adolescents. Child Development, 56, 326-341.

Downey, G., \& Coyne, J. (1990). Children of depressed parents: An integrative review. Psychological bulletin, 108, 50-76.

Duvall, E. (1946). Conceptions of parenthood. American Journal of Sociology, 52, 193-203.

Elder, G. (1974). Children of the great depression. Chicago: University of Chicago Press.

Elder, G., Conger, R., \& Foster, E. (1989). Families under economic pressure. Unpublished manuscript, University of North Carolina.

Fox, G., \& Inazu, J. (1982). The influence of mother's marital history on the mother-daughter relationship in black and white households. Journal of Marriage and the Family, 44, 143153.

Garbarino, J., \& Sherman, D. (1980). High-risk neighborhoods and high-risk families: The human ecology of child maltreatment. Child Development, 51, 188-198.

Garfinkel, I., \& McLanahan, S. (1986). Single mothers and their children: A new American dilemma. Washington, DC: Urban Institute Press. 
Garmezy, N., Masten, A., \& Tellegen, A. (1985). Life events questionnaire. Minneapolis: Project Competence, University of Minnesota.

Gersten, J., Langner, T., Eisenberg, J., \& Simcha-Fagan, O. (1977). An evaluation of the etiological role of stressful life-change events in psychological disorders. Journal of Health and Social Behavior, 18, 228-244.

Goodnow, J. (1984). Parents' ideas about parenting and development: A review of issues and recent work. In M. Lamb, A. Brown, \& B. Rogoff (Eds.), Advances in developmental psychology (Vol. 3, pp. 193-242). Hillsdale, NJ: Erlbaum.

Goodnow, J. (1988). Children's household work: Its nature and functions. Psychological Bulletin, 103, 5-26.

Hetherington, E. M., Stanley-Hagan, M., \& Anderson, E. (1989). Marital transitions: A child's perspective. American Psychologist, 44, 303-312.

Hoffman, L. W. (1984). Work, family, and the socialization of the child. In R. Parke, R. Emde, H. McAdoo, \& G. Sackett (Eds.), Review of Child Development Research: Vol. 7. The Family (pp. 223-282). Chicago: University of Chicago Press.

Hoffman, M. L. (1977). Sex differences in empathy and related behaviors. Psychological Bulletin, 84, 712-722.

Kelly, R., Sheldon, A., \& Fox, G. (1985). The impact of economic dislocation on the health of children. In J. Boulet, A. M. DeBritto, \& S. A. Ray (Eds.), The impact of poverty and unemployment on children (pp. 94-108). Ann Arbor: University of Michigan Bush Program in Child Development and Social Policy.

Kessler, R., Turner, J., \& House, J. (1988). The effects of unemployment on health in a community sample: Main, modifying, and mediating effects. Journal of Social Issues, 44, 69-86.

Kohn, M. (1959). Social class and parental values. American Journal of Sociology, 64, 337-351.

Ladner, J. (1972). Tomorrow's tomorrow: The black woman. Garden City, NJ: Anchor.

Lempers, J., Clark-Lempers, D., \& Simons, R. (1989). Economic hardship, parenting, and distress in adolescence. Child Development, 60, 25-49.

Longfellow, C., Zelkowitz, P., \& Saunders, E. (1982). The quality of mother-child relationships. In D. Belle (Ed.), Lives in stress: Women and depression (pp. 163-176). Beverly Hills: Sage.

Lurie, O. (1974). Parents' attitudes toward children's problems and toward use of mental health services: Socioeconomic differences. American Journal of Orthopsychiatry, 44, 109 . 120.

Makosky, V. P. (1982). Sources of stress: Events or conditions? In D. Belle (Ed.), Lives in stress: Women and depression (pp. 35-53). Beverly Hills: Sage.

McLoyd, V. C. (1990). The impact of economic hardship on black families and children: Psychological distress, parenting, and socioemotional development. Child Development, 61, 311-346.

McLoyd, V. C., \& Wilson, L. (1990). Maternal behavior, social support, and economic conditions as predictors of psychological distress in children. In V. C. McLoyd \& C. Flanagan (Eds.), New directions for child development, Economic stress: Effects on family life and child development (pp. 49-69). San Francisco, Jossey-Bass.

Newson, J., \& Newson, E. (1976). Seven year olds in the home environment. London: Allen \& Unwin.

Ogbu, J. (1981). Origins of human competence: A cultural-ecological perspective. Child Development, 52, 413-429.

Radloff, L. (1977). The CES-D Scale: a self-report depression scale for research in the general population. Applied Psychological Measurement, 1, 385-401.

Sandler, I. (1980). Social support resources, stress, and maladjustment of poor children. American Journal of Community Psychology, 8, 41.52.

Sandler, I., Miller, P., Short, J., \& Wolchik, S. (1989). Social support as a protective factor for children in stress. In D. Belle (Ed.), Children's social networks and social supports (pp. 277-307). New York: Wiley.

Seabrook, J. (1982). Working-class childhood. London: Camelot. 
Smith, L. (1986). The paradox of women's poverty: Wage-earning women and economic transformation. In B. Gelpi, N. Hartsock, C. Novak, \& M. Strober (Eds.), Women and poverty (pp. 121-140). Chicago: University of Chicago Press.

Stevens, J., \& Duffield, B. (1986). Age and parenting skill among black women in poverty. Early Childhood Research Quarterly, 1, 221-235.

Watson-Gegeo, K. A., \& Gegeo, D. (1989). The role of sibling interaction in child socialization. In P. Zukow (Ed.), Sibling interaction across cultures: Theoretical and methodological issues (pp. 54-76). New York: Springer-Verlag.

Weinraub, M., \& Wolf, B. (1983). Effects of stress and social supports on mother-child interactions in single- and two-parent families. Child Development, 54, 1297-1311.

Weiss, R. (1979). Growing up a little faster: The experience of growing up in a single-parent household. Journal of Social Issues, 35, 97-111.

Zill, N., \& Peterson, J. (1982). Learning to do things without help. In L. Laosa \& I. Sigel (Eds.), Families as learning environments for children (pp. 343-374). New York: Plenum Press.

Zur-Szpiro, S., \& Longfellow, C. (1982). Fathers' support to mothers and children. In D. Belle (Ed.), Lives in stress: Women and depression (pp. 145-153). Beverly Hills: Sage. 